\title{
DISCUSSING AND EVALUATING GREEN SUPPLY CHAIN SUPPLIERS: A CASE STUDY OF THE PRINTED CIRCUIT BOARD INDUSTRY IN CHINA
}

\author{
J.-J. Guo ${ }^{1} \&$ S.-B. Tsai ${ }^{2,3,4,5 *}$ \\ ${ }^{1}$ Graduate Institute of China Studies \\ Tamkang University, Taiwan \\ 103300@mail.tku.edu.tw \\ ${ }^{2}$ Zhongshan Institute \\ University of Electronic Science and Technology of China, China \\ ${ }^{3}$ China Academy of Corporate Governance \\ Nankai University, China \\ jason.tsai@tuc.com.tw \\ ${ }^{4}$ Law School \\ Nankai University, China \\ ${ }^{5}$ Department of Psychology \\ Universidad Santo Tomas de Oriente y Medio Día, Nicaragua
}

\begin{abstract}
Green supply-chain management is a novel idea that incorporates the concept of environmental protection into traditional supply-chain management in order to reduce environmental risks and impact. This study developed criteria for evaluating green suppliers on the basis of the green supply chain. The Decision-Making Trial and Evaluation Laboratory (DEMATEL) method was adopted to investigate the criteria for evaluating green suppliers, to explore inter criterion causal relationships and levels of mutual influence, and finally to discuss the mechanism for evaluating green suppliers, as well as the methods for selecting them.
\end{abstract}

\section{OPSOMMING}

Groen voorsieningskettingbestuur is ' $n$ nuwe idee wat die konsep van omgewingsbeskerming tot tradisionele voorsieningskettingbestuur byvoeg om sodoende die omgewingsrisiko's en -impak verminder. Dié studie het ' $n$ kriteria vir die beoordeling van groen verskaffers op grond van die groen voorsieningsketting ontwikkel. Die "Decision-Making Trial and Evaluation Laboratory" (DEMATEL) metode is aangepas om die kriteria vir die beoordeling van groen verskaffers te ondersoek, om die onderlinge maatstaf oorsaaklike verhoudings en vlakke van wedersydse invloed te ondersoek en om die meganisme vir die beoordeling van groen verskaffers en die metodes om hulle te kies, word bespreek.

\footnotetext{
Corresponding author
} 
Traditional supply chain management (SCM) involves planning, organising, coordinating, and controlling logistics, information flow, capital flow, and workflow; it is a customer-oriented management that connects all aspects of a supply chain. Traditional SCM emphasises the delivery of products to customers correctly and in a timely manner; however, it focuses only on using internal resources in a supply chain adequately, and does not consider the impact of a relevant project selected during the supply process on the environment and people, the rational use of resources, energy conservation, and waste disposal and recycling. Green supply chain (GSC) management should therefore possess functions that take these factors into consideration [1-3].

A GSC necessitates that suppliers consider their products and related environmental management simultaneously, and integrate the principle of environmental protection into their management mechanisms. The purpose of a GSC is to promote green products and enhance market competitiveness. In practice, several enterprises have developed pro-environmental procurement programmes, performance standards, and evaluation processes for suppliers to follow. In addition, certain enterprises listed environmentally hazardous substances, requesting that suppliers not discharge these harmful substances into the environment as waste nor use them for producing and packaging their products [4-5].

GSC management includes the entire process from product design to ultimate recycling. Walton et al. [6] indicated that a GSC includes five items: procurement, material management, transportation, packaging, and recycling/reverse logistics. Enterprises that adopt green management should consider green purchasing, transportation, pollution, and recycling during decision-making.

A GSC is a supply chain effect caused by green products promoted by the European Union (EU). EU countries understand that all parts of a supply chain are related to one another, and so they actively legislate for environmental protection instead of using moral suasion. In addition, EU countries have defined an execution timetable, hoping to promote the development of environmentally-friendly global manufacturing practices with the strong support of EU commercial markets.

To reduce effectively the impact of electrical and electronic products on the environment and on people, the EU announced the 'Waste Electrical and Electronic Equipment (WEEE) Directive' and the 'Restriction of Hazardous Substances (RoHS) in Electrical and Electronic Equipment Directive' in 2003. The WEEE Directive requires all manufacturers selling electrical and electronic products in EU countries to consider the environmental pollution caused by product waste disposals, to adopt recyclable and environmentally-friendly design concepts, and to be responsible for waste recycling and relevant costs. The RoHS Directive forbids the use of six toxic chemicals in manufacturing various types of electrical and electronic products. In addition, the EU announced the 'Directive of Eco-design Requirements of Energy-using Products' (EuP) in 2005, which stipulates that manufacturers must employ the product life cycle concept and integrate the requirement of eco-design into product design and development. The purposes of these directives are to reduce environmental pollution and energy demand, and to enhance environmental protection. Furthermore, China implemented the 'Administrative Measure on the Control of Pollution Caused by Electronic Information Products' (also known as China RoHS) in March 2007, the purpose of which was to control the use of hazardous substances in electronic information products [7-8].

The manufacturing process of printed circuit boards (PCBs) is complex. It requires multiple chemical agents and special raw materials, thus producing various types of waste water, waste liquid, and solid waste. In addition to numerous types of organic pollutants, the wastes contain substantial amounts of heavy metals such as copper, lead, and nickel. These pollutants, which have high pollution intensity, also feature properties that become increasingly problematic with increasing product levels. Failures to prevent contamination 
will result in severe environmental pollution. Consequently, finding a way to reduce production-induced environmental pollution throughout the entire PCB industry chain has been a critical concern of the Chinese government and businesses in China.

China is one of the world's largest PCB manufacturers, and will remain at the top because of its advantages in production costs. According to statistics from the China Printed Circuit Association, the world's PCB output value was US\$59.79 billion, with China accounting for US\$25.53 billion and representing 42.7 per cent of the global output, followed by Japan (14.4 per cent) and Taiwan (13.4 per cent).

This study adopted the Decision-Making Trial and Evaluation Laboratory (DEMATEL) method to develop criteria for evaluating green suppliers on the basis of the GSC. First, criteria for evaluating green suppliers were explored. Second, the causal relationshipships between the criteria and their levels of mutual influence were investigated. Finally, the mechanism for evaluating green suppliers and the methods for selecting them was discussed.

\section{LITERATURE REVIEW}

\subsection{Supply Chain and Green Supply Chain}

The Global Supply Chain Forum [9] defined SCM as "the integration of key business processes from end user through original suppliers that provides products, services, and information that add value for customers and other stakeholders". A supply chain is a system by which an enterprise provides and delivers its products or services to customers. A supply chain network consists of suppliers, manufacturers, distributors, retailers, and consumers, in which each component has a major impact on overall operation [1, 9-11].

Handfield et al. [9] stated that a supply chain includes processes such as customer ordering, production and product delivery, and that numerous companies play a functional role in a supply chain, correctly produce products, and deliver products to customers in a timely manner. These functions include accepting customer orders, production planning, manufacturing, quality control, packaging, delivery, and recycling.

Humphreys et al. [12] indicated that the purpose of SCM is mainly to manage the logistics and information flow among suppliers, manufacturers, assemblers, and distribution systems [13].

According to traditional perspectives, a supply chain is an internal process of a manufacturing enterprise [14]. The supply chain concept focuses on the internal operation and the use of the enterprise's resources. In addition, a supply chain is a process that emphasises the importance of external connections with other enterprises; specifically, a supply chain is a conversion process in which materials are converted into products through manufacturing, assembly, distribution, and retailing in various enterprises, and these products are subsequently delivered to customers. In addition, SCM highlights the importance of corporate networks, such as the front-end relationship among core enterprises, suppliers, and the suppliers of suppliers, and the back-end relationship among core enterprises, customers, and the customers of customers. Based on this corporate network, GSC comprehensively considers environmental impacts in order to protect the environment and reduce resource consumption during the processes of obtaining materials, processing, packaging, storing, delivering, and disposing of products [13-14].

Establishing a GSC has both advantages and disadvantages. The advantages are listed as follows: enterprises that encounter fierce market competition can form an alliance to implement a GSC and therefore integrate with upstream and downstream enterprises in the GSC to complement one another and produce benefits for the entire supply chain. In addition, GSC-based enterprises can establish a positive image, signifying that the enterprises produce safe and reliable products and accept social responsibility, thereby enhancing the enterprises' green image and obtaining customer loyalty. 
Regarding the disadvantages, although a GSC can enhance the efficiency of resource use and reduce costs to a certain degree, green recycling and waste disposal requires substantial cost, thus generating deficits. In addition, the technology and knowledge required for implementing a GSC are currently inadequate. Although a GSC can be established in theory, technologies and measures for developing green products and disposing of waste require improvement.

\subsection{Evaluation of GSC suppliers}

GSC management includes the entire process from product design to recycling. The items used to evaluate green suppliers include green design, green materials, green suppliers, green production, green selling and packaging, green transportation, and green recycling.

As indicated by Noci [15], to ensure that suppliers satisfy the requirements of a green corporate environment, the process of choosing a green supplier comprises four stages:

1. Formulate strategies for improving the product environment according to the objectives of a corporate environment.

2. Determine the main environmental evaluation standards according to existing suppliers, technologies, and environmental regulations.

3. Choose a decision-supporting method to analyse the environmental performance of suppliers.

4. Implement and monitor procedures.

Walton et al. [6] considered that, because of rigorous regulations, suppliers must engage in environmentally-friendly behaviour to provide low-cost and satisfactory services. Walton et al. also reported that green production, design, environment, and transportation are the essential criteria in supplier evaluation and selection. Handfield et al. [9] used the analytic hierarchy process (AHP) to evaluate and select green suppliers. The evaluation index comprises four dimensions: the effectiveness of an environmental management system, compliance with regulations, internal control procedures, and green corporate image.

According to Zhu and Sarkis [16], the GSC dimensions requiring investigation were green design, green purchasing, green management, green production, and reverse logistics. Hervani et al. [17] emphasised several dimensions of GSC management, including green design, green materials, manufacturing, recycling, and environmental performance evaluation. Srivastava [18] noted that GSC management incorporated green awareness into SCM, and that the awareness is reflected in product design, raw material acquisition and selection, manufacturing processes, final product delivery to customers, and the management preceding product disposal. Zhang [19] stated that green procurement and green supplier management substantially influence medium-sized and large enterprises. Zhang selected and investigated 28 companies and used multivariate analysis to determine a set of green-supplier evaluation and selection standards. Tsai et al. [20] proposed four evaluation dimensions for the GSC: green design, green production, green marketing, and green recycling. Although the four dimensions are general principles, their levels of importance and application vary by country and by company. In summary, this study argued that GSC management covers the entire process from product design to final recycling, including items such as green designs, green materials, green suppliers, green production, green marketing and packaging, green transportation, and green recycling.

Based on the previous discussion, two weaknesses were discovered in previous studies on supplier evaluation and selection. First, most studies have assumed that evaluation criteria are independent of each other and do not influence one another. Second, several studies have assumed that all criteria have equal weight. These two weaknesses in the extant literature affect the real evaluation of currently developing GSCs. 
This study employed the DEMATEL method to investigate the criteria for evaluating green suppliers, explore the causal relationshipships between the criteria and their levels of mutual influence, and discuss the mechanism for evaluating green suppliers, as well as the methods for selecting them.

\subsection{Evaluation criteria for green suppliers}

A criteria system for assessing green suppliers assists a company in improving resource use, reducing resource consumption, and enhancing corporate image. By conducting a literature review, this study elucidates GSC management and green-supplier evaluation, establishing evaluation criteria for green suppliers.

The evaluation criteria system used in this study comprises four dimensions and 12 criteria. The four dimensions and detailed content are presented in Table 1.

1. Green production: green design, green material use, waste reduction, and energy conservation.

2. Green manufacturing environment: reduction of air pollution, reduction of wastewater discharge, and reduction of harmful substance use.

3. Green management: green management system, green selling, and green corporate image.

4. Green packaging and recycling: green transportation, green packaging, and product recyclability.

Table 1: Green-supplier evaluation criteria

\begin{tabular}{ll}
\hline Dimensions & Criteria \\
\hline a: Green production & a1: green design \\
& a2: green material use \\
& a3: waste reduction and energy conservation \\
b: Green manufacturing environment & b1: reduction of air pollution \\
& b2: reduction of wastewater discharge \\
& b3: reduction of harmful substance use \\
c: Green management & c1: green management system \\
& c2: green selling \\
& c3: green corporate image \\
d: Green transportation and recycling & d1: green transportation \\
& d2: green packaging \\
& d3: product recyclability \\
\hline
\end{tabular}

\subsection{The DEMETEL method}

The DEMATEL method can analyse the intricate relationships and associations between criteria in complex management problems to simplify the problems effectively. This method was developed by the Battelle Memorial Institute of the Geneva Research Center [20] to resolve conflicts between technology and people. The method has mostly been applied to investigating problematic structures in the world and analysing problems with complex structures; consequently, current studies, models, and data can be developed, adjusted, and reviewed for exploring convoluted problems that concern people at this time, such as race, hunger, environmental protection, and energy [21].

The DEMATEL method can be used to understand and analyse complex causal relationshipships between problems in business departments effectively. By observing the level of mutual influence between two elements, researchers can explicitly quantify and analyse the intricate relationships between problems. Furthermore, matrices and relevant mathematical theories can be adopted to calculate the causal relationshipships and strengths of influence between the overall elements. These results facilitate systematic and effective clarification of the structure of the complex causal relationships between various elements and criteria, selection and planning of feasible solutions for major and minor problems, and 
identification of the method by which causal relationships determine people's dynamic decision-making behaviour.

In recent years, DEMATEL has been widely employed to solve problems in various fields. For example, Tamura et al. [22] adopted DEMATEL and level of importance to explore factors and improvements in customer food anxiety. Lin and Wu [23] applied fuzzy DEMATEL to investigate the problems of group decision-making. Lee et al. [24] employed the Kano model and DEMATEL to analyse causal relationships and levels of mutual influence to identify the core problems in conditions for winning purchase orders, using the case of Taiwan's industrial computer industry as their study example. Lee and Hsieh [24] adopted DEMATEL to analyse the causal relationships between the service attributes of the telecommunications industry to adjust the importance levels of service attributes and solve problems related to competitiveness. Tsai et al. [25] used DEMATEL to determine how manufacturing companies win purchase orders, proposing apt competitive strategies.

The DEMATEL method entails the following calculation procedure:

Step 1: Establish a measuring scale and determine the levels of causal relationships between the elements.

Literature reviews, brainstorming, and expert opinions are used to enumerate and define the factors that influence a complex system. Subsequently, a scale measuring the level of influence is designed to compare any two elements, thus determining the levels of causal relationships between them.

Step 2: Establish a direct-relation matrix.

After clarifying the meanings of the measuring scale, researchers can conduct a questionnaire, inviting experts to participate in a pairwise comparison of the elements according to their relationships and levels of mutual influence. Finally, a direct-relation matrix is formed, in which every figure represents a level of mutual influence between two elements, and every figure along the diagonal (upper left to lower right) of the direct-relation matrix is designated as 0 .

$$
X=\left[\begin{array}{cccc}
0 & x_{12} & \cdots & x_{1 n} \\
x_{21} & 0 & \cdots & x_{2 n} \\
\vdots & \vdots & \ddots & \vdots \\
x_{n 1} & x_{n 2} & \cdots & 0
\end{array}\right]
$$

Step 3: Calculate the normalised direct-relation matrix with column vectors and maximal figures as normalisation baselines.

$$
\begin{gathered}
\lambda=\frac{1}{\operatorname{Max}\left(\sum_{j=1}^{n} x_{i j}\right)} \\
N=\lambda X
\end{gathered}
$$

Step 4: Calculate the direct/indirect relation matrix $T$, namely the total-relation matrix.

$$
T=\lim _{k \rightarrow \infty}\left(N+N^{2}+\cdots+N^{k}\right)=N(I-N)^{-1}
$$

where I denotes the identity matrix. 
Step 5: Calculate the sum of the elements of each column and each row.

The elements of every column and row in the total-relation matrix T are totalled; $D_{i}$ is designated as the sum of Row $\mathrm{i}$, and $R_{j}$ represents the sum of Column $\mathrm{j}$. Consequently, both $D_{i}$ and $R_{i}$ involve indirect and direct influence.

$$
\begin{aligned}
& D_{i}=\sum_{j=1}^{n} t_{i j} \quad(i=1,2, \ldots, n) \\
& R_{j}=\sum_{i=1}^{n} t_{i j} \quad(j=1,2, \ldots, n)
\end{aligned}
$$

Step 6: Draw a DEMATEL causal-relation diagram.

$(D+R)$ is defined as the prominence $(k=i=j=1,2, \ldots . n)$, in which Criterion $k$ signifies the sum (total relation) of the influence of the criterion on other criteria, as well as their influence on it (hereafter referred to as 'influencing and being influenced by other criteria', and from which the level of importance of Criterion $k$ in the problems can be determined. ( $D$ $-R$ ) is defined as the relation, that is the difference between Criterion $k$ 's level of influence on other criteria and their influence on it, and from which Criterion k's levels of causal relationships in all of the problems can be identified. A positive value for $(D-R)$ indicates that the criterion is more a cause than an effect, whereas a negative value reveals the opposite. A causal-relation diagram is drawn with $(D+R)$ on the $y$-axis and $(D-R)$ on the $x$-axis. By simplifying complex causal relationships into intelligible visual structures, decision-makers can discern the category of each factor according to its position in the diagram and make appropriate decisions, solving problems according to their level of influence.

1. Positive $\left(D_{k}-R_{k}\right)$ and high $\left(D_{k}+R_{k}\right)$ : These levels of influencing and being influenced by other criteria indicate that the criterion's total influence is considerable; moreover, this criterion should be categorised as a cause because its influence over others surpasses the influence of others over it. Consequently, this criterion has the attribute of a cause and is a driver for problem-solving.

2. Positive $\left(D_{k}-R_{k}\right)$ and low $\left(D_{k}+R_{k}\right)$ : A high influence over other criteria and low total influence indicate that the criterion should be in the cause category. In other words, the criterion is independent and can only affect a low number of other criteria.

3. Negative $\left(D_{k}-R_{k}\right)$ and high $\left(D_{k}+R_{k}\right)$ : The criterion's influence over other criteria is lower than the influence of others over it. However, the total influence is high, and therefore the criterion is categorised as an effect. In other words, this criterion is a core problem that requires a solution; however, it cannot be directly mitigated because it has the attribute of an effect.

4. Negative $\left(D_{k}-R_{k}\right)$ and low $\left(D_{k}+R_{k}\right)$ : This criterion's influence over other criteria is lower than the influence of others over it, and its total influence is relatively low. Therefore, this criterion is categorised as an effect with low total influence. In other words, this criterion is independent and influenced only by a low number of other criteria.

\section{RESULTS AND DISCUSSION}

\subsection{Research questionnaire}

The DEMATEL questionnaire for green suppliers included four dimensions and 12 evaluation criteria. The four dimensions were green production, green manufacturing environment, green management, and green transportation and recycling. The 12 evaluation criteria comprised green design (a1), green material use (a2), waste reduction and energy 
conservation (a3), reduction of air pollution (b1), reduction of wastewater discharge (b2), reduction of harmful substance use (b3), green management system (c1), green selling (c2), corporate green image $(\mathrm{c} 3)$, green transportation (d1), green packaging (d2), and product recyclability $(\mathrm{d} 3)$.

The DEMATEL questionnaire was distributed from 1 to 20 April 2014. This study invited a group of experts to express their personal opinions about the criteria for evaluating green suppliers. A seven-point rating scale was adopted, with '6' denoting the highest level of influence and ' 0 ' denoting an absence of influence. The questionnaire respondents comprised 15 experts, including four general managers from electronic system manufacturers that purchase PCBs, four general managers of $P C B$ companies, four professionals, and three officials from the government's Department of Environmental Protection. The authors visited every respondent, explained the content of the questionnaire in person, and handed the questionnaire to the respondent to complete. A total of 15 formal questionnaires were distributed and 15 valid questionnaires were retrieved (a valid return rate of $100 \%)$.

\subsection{Calculation results}

Table 2 presents the results of the expert opinion survey. The table of 12 criteria was compiled after the scores of the 15 experts were averaged, with the resulting fractions being rounded up one decimal point. The table contains 132 mutual influence values, after 12 influence levels with values of 0.0 along the diagonal of the matrix, where the criteria were paired with themselves, had been deleted from the original 144 cells (Table 2 ).

Table 2: The direct-relation matrix $X$

\begin{tabular}{lllllllllllll}
\hline Criteria & a1 & a2 & a3 & b1 & b2 & b3 & c1 & c2 & c3 & d1 & 22 & d3 \\
\hline a1 & 0.0 & 3.3 & 2.5 & 1.3 & 2.3 & 2.8 & 5.1 & 3.6 & 3.5 & 0.7 & 3.7 & 4.2 \\
a2 & 2.5 & 0.0 & 2.4 & 1.9 & 1.3 & 2.5 & 5.3 & 2.8 & 4.6 & 0.6 & 4.2 & 3.5 \\
a3 & 1.4 & 1.6 & 0.0 & 3.1 & 3.8 & 1.6 & 4.2 & 2.5 & 4.1 & 0.9 & 3.6 & 1.2 \\
b1 & 0.3 & 0.0 & 2.3 & 0.0 & 1.5 & 0.0 & 4.5 & 2.8 & 4.9 & 0.3 & 0.0 & 0.0 \\
b2 & 0.5 & 0.0 & 1.8 & 0.0 & 0.0 & 1.8 & 5.1 & 3.8 & 4.6 & 0.0 & 0.0 & 0.0 \\
b3 & 1.2 & 1.3 & 2.5 & 0.3 & 1.1 & 0.0 & 4.8 & 3.5 & 3.7 & 0.8 & 2.8 & 3.2 \\
c1 & 1.7 & 1.3 & 1.2 & 1.4 & 1.2 & 1.2 & 0.0 & 2.4 & 3.2 & 0.8 & 0.5 & 1.3 \\
c2 & 0.8 & 1.5 & 0.5 & 0.6 & 0.5 & 1.1 & 2.5 & 0.0 & 4.2 & 0.8 & 0.9 & 1.4 \\
c3 & 0.9 & 0.6 & 0.5 & 0.5 & 0.3 & 1.2 & 2.4 & 4.0 & 0.0 & 1.0 & 1.1 & 0.0 \\
d1 & 0.3 & 0.0 & 1.0 & 2.5 & 0.0 & 0.5 & 2.1 & 0.6 & 2.5 & 0.0 & 0.0 & 0.0 \\
d2 & 0.5 & 1.2 & 0.8 & 0.0 & 0.0 & 0.7 & 2.2 & 1.9 & 3.2 & 0.0 & 0.0 & 3.5 \\
d3 & 1.8 & 2.3 & 0.7 & 0.0 & 0.0 & 0.8 & 3.0 & 2.6 & 2.5 & 0.0 & 0.5 & 0.0 \\
\hline
\end{tabular}

Subsequently the normalised direct-relation matrix was calculated. Column vectors and maximal figures were used as normalised baselines in calculating the normalised direct-relation matrix. According to Equation (2), the reciprocal of the maximal figure between all column sums was $\lambda$. After the calculation in Equation (3) was performed, the direct-relation matrix $X$ was multiplied by $\lambda$ to obtain the normalised direct-relation matrix $N$. The influence coefficients were rounded up two decimal points (Table 3 ).

Equation (4) was then used to calculate the direct/indirect relation matrix $T$, and the obtained influence coefficients were rounded up to two decimal points (Table 4).

Afterwards, Equations (5) and (6) were adopted to calculate the sum of each row $D_{i}$, the sum of each column $R_{j}$, values of prominence $\left(D_{i}+R_{j}\right)$, and values of relation $\left(D_{i}-R_{j}\right)$. The calculation results are presented in Table 5 . In addition, the 12 criteria were drawn into a diagram with prominence and relation as its axes (see Figure 1).

\subsection{Discussion}

The criteria were classified and discussed in detail using relation $(D-R)$ and prominence $(D+$ $R$ ) to investigate the levels of mutual influence and causal relationships. 
Table 3: The normalised direct-relation matrix $N$

\begin{tabular}{lllllllllllll}
\hline Criteria & $\mathrm{a} 1$ & $\mathrm{a} 2$ & $\mathrm{a} 3$ & $\mathrm{~b} 1$ & $\mathrm{~b} 2$ & $\mathrm{~b} 3$ & $\mathrm{c1}$ & $\mathrm{c} 2$ & $\mathrm{c} 3$ & $\mathrm{~d} 1$ & 22 & $\mathrm{~d} 3$ \\
\hline a1 & 0.00 & 0.10 & 0.08 & 0.04 & 0.07 & 0.08 & 0.15 & 0.11 & 0.10 & 0.02 & 0.11 & 0.13 \\
a2 & 0.07 & 0.00 & 0.07 & 0.05 & 0.04 & 0.08 & 0.16 & 0.08 & 0.14 & 0.02 & 0.12 & 0.10 \\
a3 & 0.05 & 0.04 & 0.00 & 0.10 & 0.11 & 0.05 & 0.13 & 0.07 & 0.12 & 0.03 & 0.10 & 0.04 \\
b1 & 0.01 & 0.00 & 0.07 & 0.00 & 0.04 & 0.00 & 0.13 & 0.08 & 0.09 & 0.02 & 0.00 & 0.00 \\
b2 & 0.02 & 0.00 & 0.05 & 0.00 & 0.00 & 0.08 & 0.16 & 0.11 & 0.13 & 0.00 & 0.00 & 0.00 \\
b3 & 0.04 & 0.04 & 0.07 & 0.01 & 0.04 & 0.00 & 0.14 & 0.10 & 0.11 & 0.02 & 0.08 & 0.10 \\
c1 & 0.05 & 0.04 & 0.04 & 0.04 & 0.03 & 0.04 & 0.00 & 0.07 & 0.10 & 0.02 & 0.02 & 0.06 \\
c2 & 0.03 & 0.04 & 0.05 & 0.02 & 0.01 & 0.04 & 0.07 & 0.00 & 0.13 & 0.04 & 0.02 & 0.04 \\
c3 & 0.02 & 0.02 & 0.02 & 0.01 & 0.01 & 0.04 & 0.07 & 0.13 & 0.00 & 0.04 & 0.04 & 0.00 \\
d1 & 0.01 & 0.00 & 0.04 & 0.07 & 0.00 & 0.02 & 0.07 & 0.02 & 0.08 & 0.00 & 0.00 & 0.00 \\
d2 & 0.02 & 0.04 & 0.02 & 0.00 & 0.00 & 0.03 & 0.07 & 0.05 & 0.10 & 0.00 & 0.00 & 0.10 \\
d3 & 0.05 & 0.07 & 0.02 & 0.00 & 0.00 & 0.03 & 0.09 & 0.08 & 0.07 & 0.00 & 0.02 & 0.00 \\
\hline
\end{tabular}

Table 4: The total-relation criteria matrix $T$

\begin{tabular}{lllllllllllll}
\hline Criteria & a1 & a2 & a3 & b1 & b2 & b3 & c1 & c2 & c3 & d1 & 22 & d3 \\
\hline a1 & 0.08 & 0.18 & 0.17 & 0.10 & 0.14 & 0.17 & 0.36 & 0.29 & 0.32 & 0.07 & 0.20 & 0.24 \\
a2 & 0.14 & 0.08 & 0.16 & 0.11 & 0.10 & 0.16 & 0.35 & 0.24 & 0.33 & 0.07 & 0.20 & 0.20 \\
a3 & 0.11 & 0.10 & 0.08 & 0.14 & 0.16 & 0.13 & 0.30 & 0.22 & 0.30 & 0.07 & 0.17 & 0.12 \\
b1 & 0.05 & 0.04 & 0.11 & 0.03 & 0.07 & 0.04 & 0.22 & 0.16 & 0.18 & 0.05 & 0.04 & 0.04 \\
b2 & 0.06 & 0.05 & 0.10 & 0.04 & 0.04 & 0.13 & 0.26 & 0.21 & 0.25 & 0.03 & 0.05 & 0.06 \\
b3 & 0.10 & 0.10 & 0.14 & 0.06 & 0.09 & 0.07 & 0.29 & 0.23 & 0.26 & 0.06 & 0.15 & 0.18 \\
C1 & 0.09 & 0.08 & 0.09 & 0.08 & 0.07 & 0.08 & 0.12 & 0.17 & 0.21 & 0.05 & 0.07 & 0.11 \\
C2 & 0.06 & 0.08 & 0.09 & 0.05 & 0.05 & 0.08 & 0.18 & 0.09 & 0.23 & 0.06 & 0.07 & 0.09 \\
c3 & 0.05 & 0.06 & 0.06 & 0.04 & 0.04 & 0.08 & 0.16 & 0.19 & 0.09 & 0.06 & 0.07 & 0.05 \\
d1 & 0.03 & 0.02 & 0.06 & 0.09 & 0.02 & 0.04 & 0.13 & 0.08 & 0.14 & 0.02 & 0.03 & 0.03 \\
d2 & 0.05 & 0.08 & 0.06 & 0.03 & 0.03 & 0.07 & 0.16 & 0.13 & 0.18 & 0.02 & 0.04 & 0.15 \\
d3 & 0.09 & 0.11 & 0.07 & 0.03 & 0.03 & 0.07 & 0.19 & 0.16 & 0.17 & 0.03 & 0.07 & 0.06 \\
\hline
\end{tabular}

Table 5:. DEMATEL prominence and relation results

\begin{tabular}{lcccc}
\hline Criteria & $\mathbf{D}$ & $\mathbf{R}$ & $\mathbf{D}+\mathbf{R}$ & $\mathbf{D}-\mathbf{R}$ \\
a1 & 2.31 & 0.91 & 3.22 & 1.40 \\
a2 & 2.14 & 0.98 & 3.13 & 1.16 \\
a3 & 1.91 & 1.19 & 3.10 & 0.72 \\
b1 & 1.04 & 0.81 & 1.85 & 0.23 \\
b2 & 1.26 & 0.83 & 2.09 & 0.43 \\
b3 & 1.72 & 1.11 & 2.84 & 0.61 \\
c1 & 1.20 & 2.69 & 3.89 & -1.49 \\
c2 & 1.14 & 2.18 & 3.32 & -1.04 \\
c3 & 0.95 & 2.66 & 3.61 & -1.71 \\
d1 & 0.68 & 0.59 & 1.27 & 0.09 \\
d2 & 0.99 & 1.17 & 2.16 & -0.18 \\
d3 & 1.09 & 1.32 & 2.40 & -0.23 \\
Mean & & & 2.74 & 0.00 \\
\hline
\end{tabular}

1. High relation and high prominence: green design (a1), green material use (a2), waste reduction and energy conservation (a3), and reduction of harmful substance use (b3). These four criteria were categorised as causes and core items that influenced other attributes. In other words, they were drivers for problem-solving.

2. High relation and low prominence: reduction of air pollution (b1), reduction of wastewater discharge (b2), and green transportation (d1). These three attributes could influence a small number of other attributes, although to a relatively lesser extent.

3. Low relation and high prominence: green management system (c1), green selling (c2), and green corporate image (c3). These three attributes were in the category of effect. This type of attribute was influenced by other attributes and could not be directly improved.

4. Low relation and low prominence: green packaging (d2) and product recyclability (d3). These two criteria were influenced by other criteria, although to an extremely low extent. In other words, this type of attribute was relatively independent. 


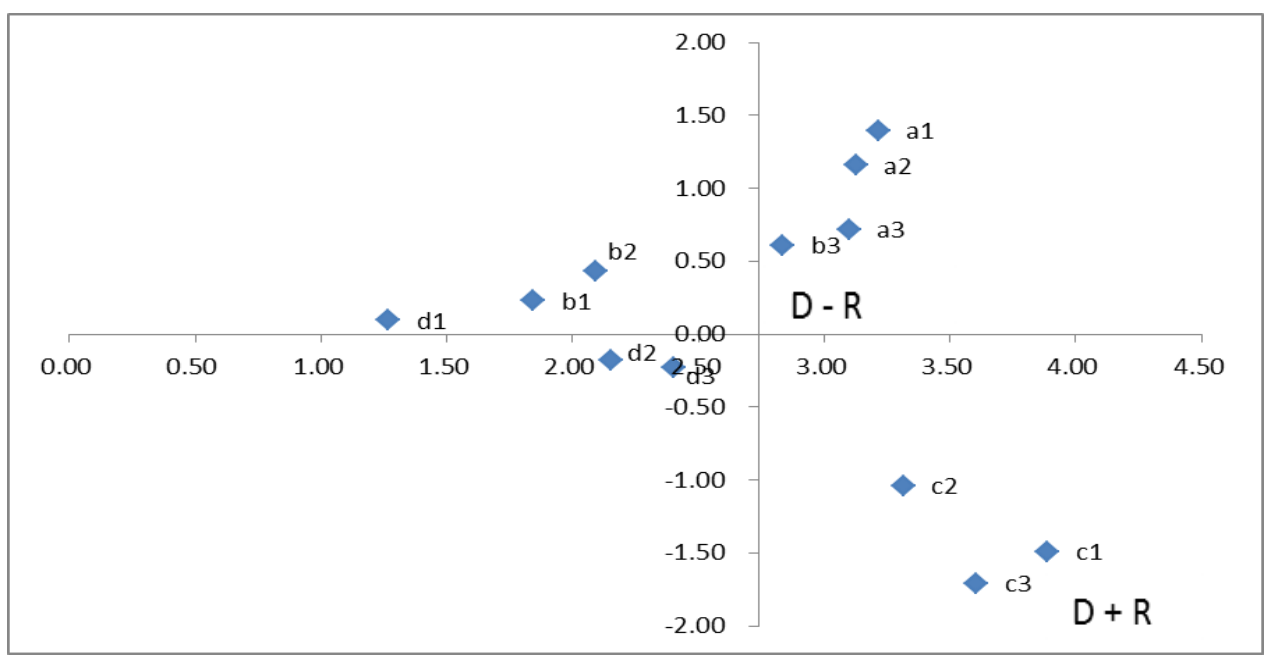

Figure 1: DEMATEL distribution of the 12 criteria

According to the aforementioned analyses on influence levels and causal relationships, this study determined that green design (a1) is the core criterion of corporate development by which enterprises can actively propose a business strategy entailing green design for enhancing green performance. The criterion of green material use (a2) also indicated that businesses should adopt green concepts when selecting raw materials and purchasing green materials from suppliers. The criterion of waste reduction and energy conservation (a3) revealed that enterprises should reduce hazardous waste and energy consumption during the manufacturing process to achieve the eco-friendly goal of having green suppliers. Moreover, the criterion of the reduction of harmful substance use (b3) indicated that businesses should actively prevent the use of hazardous substances to reduce air and water pollution, in addition to improving green environmental performance.

Furthermore, the four criteria of green design (a1), green material use (a2), waste reduction and energy conservation (a3), and reduction of harmful substance use (b3) were the major problem-solving factors. Using the four criteria to enhance green performance can subsequently promote the other performance-improving criteria.

\section{CONCLUSION}

The GSC requires suppliers to consider their products and environment-related management comprehensively, and to incorporate the principles of environmental protection into their management mechanisms, thus rendering their products more eco-friendly and enhancing their market competitiveness. A company can improve its resource use, reduce energy consumption, and boost its image by establishing criteria for evaluating green suppliers.

This study has developed criteria for evaluating green suppliers on the basis of the GSC. The DEMATEL method was adopted to investigate the criteria for evaluating green suppliers, to explore intercriterion causal relationships and levels of mutual influence, and to discuss the mechanism for evaluating green suppliers and the methods for selecting them.

Twelve criteria for evaluating green suppliers were analysed, in addition to the criteria's levels of mutual influence and causal relationships. This study determined that the four criteria of green design (a1), green material use (a2), waste reduction and energy conservation (a3), and reduction of harmful substance use (b3) are the major problem-solving factors. Improving the green performance of the four criteria can promote other performance-enhancing criteria and thus achieve the goal of green suppliers. 
The DEMATEL method can be used to understand and analyse complex causal relationships between problems in business departments effectively. By observing the level of mutual influence between two elements, researchers can explicitly quantify and analyse the intricate relationships between problems. Furthermore, matrices and relevant mathematical theories can be adopted to calculate the causal relationships and strengths of influence between the overall elements. These results facilitate systematic and effective clarification of the structure of the complex causal relationships between various elements and criteria, selection and planning of feasible solutions for major and minor problems, and identification of the method by which causal relationships determine people's dynamic decision-making behaviour.

\section{REFERENCES}

[1] Chandraprakaikul, W., Baines, T.S. \& Lim, R.Y. 2010. Strategic positioning of manufacturing operations within global supply chains. Proceedings of the Institution of Mechanical Engineers, Part B: Journal of Engineering Manufacture, 224(5), pp. 831-844.

[2] Kumar, S., Teichman, S. \& Timpernagel, T. 2012. A green supply chain is a requirement for profitability. International Journal of Production Research, 50(5), pp. 1278-1296.

[3] Tsireme, A.I., Nikolaou, E.I., Georgantzis, N. \& Tsagarakis, K.P. 2012. The influence of environmental policy on the decisions of managers to adopt G-SCM practices. Clean Technologies and Environmental Policy, 14(5), pp. 953-964.

[4] Ahi, P. \& Searcy, C. 2013. A comparative literature analysis of definitions for green and sustainable supply chain management. Journal of Cleaner Production, 52(8), pp. 329-341.

[5] Blome, C., Hollos, D. \& Paulraj, A. 2014. Green procurement and green supplier development: Antecedents and effects on supplier performance. International Journal of Production Research, 52(1), pp. 32-49.

[6] Walton, S.V., Haldfield, R.B. \& Melnyk, S.A. 1998. The green supply chain: Integrating suppliers into environmental management processes. International Journal of Purchasing and Materials Management, 34(2), pp. 2-11.

[7] Gerardo, J., Michael, A.G. \& Raymond, L.S. 2014. Expanding GREENSCOPE beyond the gate: A green chemistry and life cycle perspective. Clean Technologies and Environmental Policy, 16(4), pp. 703-717.

[8] Lin, W.J., Jiang, Z.B., Liu, R. \& Wang, L. 2014. The bullwhip effect in hybrid supply chain. International Journal of Production Research, 52(7), pp. 2062-2084.

[9] Handfield, R., Walton, S.V., Sroufe, R. \& Melnyk, S.A. 2002. Applying environmental criteria to supplier assessment: A study in the application of Analytical Hierarchy Process. European Journal of Operational Research, 141, pp. 70-87.

[10] Sadegheih, A., Li, D., Sribenjachot, S. \& Drake, P.R. 2010. Applying mixed integer programming for green supply chain management. South African Journal of Industrial Engineering, 21(2), pp. 13-24.

[11] Lee, C.T., Chiu, H.N., Yeh, R.H. \& Huang, D.K. 2012. Application of a fuzzy multilevel multiobjective production planning model in a network product manufacturing supply chain. Proceedings of the Institution of Mechanical Engineers, Part B: Journal of Engineering Manufacture, 226(12), pp. 2064-2074.

[12] Humphreys, P., Mclvor, R. \& Chan, F. 2003. Using case-based reasoning to evaluate supplier environmental management performance. Expert Systems with Applications, 25(2), pp. 141-153.

[13] Hsu, C.W., Kuo, T.C., Chen, S.H. \& Hu, A.H. 2013. Using DEMATEL to develop a carbon management model of supplier selection in green supply chain management. Journal of Cleaner Production, 56(10), pp. 164-172.

[14] Ramanathan, U., Bentley, Y. \& Pang, G. 2014. The role of collaboration in the UK green supply chains: An exploratory study of the perspectives of suppliers, logistics and retailers. Journal of Cleaner Production, 70(5), pp. 231-241.

[15] Noci, G. 1997. Designing green vendor rating systems for the assessment of a supplier's environmental performance. European Journal of Purchasing \& Supply Management, 3(2), pp. 103-114.

[16] Zhu, Q. \& Sarkis, J. 2004. Relationships between operational practices and performance among early adopters of green supply chain management practices in Chinese manufacturing enterprises. Journal of Operations Management, 22(3), pp. 265-289.

[17] Hervani, A.A., Helms, M.M. \& Sarkis, J. 2005. Performance measurement for green supply chain management. Benchmarking: An International Journal, 12(4), pp. 330-353.

[18] Srivastava, S.K. 2007. Green supply chain management: A state-of-the-art literature review. International Journal of Management Reviews, 5, pp. 53-80. 
[19] Zhang, J., Knight, L., Harland, C., Humby, S. \& James, K. 2007. An analysis of research into the future of purchasing and supply management. Journal of Purchasing \& Supply Management, 13, pp. 69-83.

[20] Gabus, A. \& Fontela, E. 1973. Perceptions of the world problematique: Communication procedure, communicating with those bearing collective responsibility. DEMATEL report No. 1. Geneva, Switzerland: Battelle Geneva Research Center.

[21] Fontela, E., \& Gabus, A. 1976. The DEMATEL Observer. DEMATEL 1976 Report. Switzerland, Geneva: Battelle Geneva Research Center.

[22] Tamura, H., Okanishi, H. \& Akazawa, K. 2006. Decision support for extracting and dissolving consumers' uneasiness over foods using stochastic DEMATEL. Journal of Telecommunications and Information Technology, 4, pp. 91-95.

[23] Lin, C.J. \& Wu, W.W. 2008. A causal analytical method for group decision making under fuzzy environment. Expert System with Applications, 34(1), pp. 205-213.

[24] Lee, Y.C. \& Hsieh, Y.F. 2011. Integration of revised simultaneous importance performance analysis and decision making trial and evaluation laboratory - A study of mobile telecommunication industry in Taiwan. African Journal of Business Management, 5(6), pp. 2312-2321.

[25] Tsai, S.B., Lee, Y.C., Wu, C.H. \& Guo, J.J. 2013. Examining how manufacturing corporations win orders. South African Journal of Industrial Engineering, 24(3), pp. 112-124. 